\title{
Review
}

Filippo Ceccato* and Carla Scaroni

\section{Central adrenal insufficiency: open issues regarding diagnosis and glucocorticoid treatment}

https://doi.org/10.1515/cclm-2018-0824

Received August 2, 2018; accepted October 13, 2018; previously published online November 14, 2018

\begin{abstract}
Background: Central adrenal insufficiency (CAI) is characterized by impaired adrenocorticotropin (ACTH) secretion because of a disease or injury to the hypothalamus or the pituitary, leading to a reduced cortisol production. CAI suspicion arises more frequently in patients with pituitary tumors, cranial irradiation/surgery/injury/infections, as well as after exogenous glucocorticoid withdrawal. Nevertheless, a late diagnosis is not uncommon because CAI may present with nonspecific signs or symptoms, as fatigue or hyponatremia.
\end{abstract}

Content: The PubMed database was searched (years 1980-2018), using “central adrenal insufficiency" and "ACTH deficiency" as keywords. Subsequently, reference sections of the retrieved articles were searched.

Summary: Dynamic tests are needed when morning basal cortisol levels are not sufficient to exclude or to confirm CAI. Short Synacthen Test (SST) is the most used, and Endocrine Society's guidelines recommend a cortisol peak $>500 \mathrm{nmol} / \mathrm{L}$ to exclude CAI. Despite thresholds, understanding the pretest probability of ACTH deficiency (the clinical background of the patient) is essential because the diagnostic accuracy of SST in case of a negative result is suboptimal. Glucocorticoid replacement therapy, able to replicate cortisol circadian rhythm, is required in patients with $\mathrm{CAI}$; fludrocortisone treatment is not necessary. Short-acting glucocorticoid drugs (hydrocortisone or cortisone acetate) are the most used; lower doses than previously used are nowadays recommended

*Corresponding author: Filippo Ceccato, MD, Endocrinology Unit, Department of Medicine DIMED, University-Hospital of Padova, Via Ospedale Civile, 105-35128 Padova, Italy; and Department of Neurosciences DNS, University of Padova, Padova, Italy, Phone: +39 049 8212559, Fax: +39 049 657391; E-mail: ceccato.filippo@gmail.com. https://orcid.org/0000-0003-1456-8716

Carla Scaroni: Endocrinology Unit, Department of Medicine DIMED, University-Hospital of Padova, Via Ospedale Civile, Padova, Italy to reduce cortisol-related comorbidities. Promising results have been obtained with modified-release hydrocortisone, especially regarding glucose metabolism in patients with primary adrenal insufficiency.

Outlook: An accurate clinical diagnosis and a careful individualized therapy are mandatory in patients with CAI.

Keywords: adrenal insufficiency; central hypoadrenalism; corticotropin test; hydrocortisone.

\section{Introduction}

A functional hypothalamic-pituitary-adrenal (HPA) axis is essential for normal health and life expectancy. Adrenal insufficiency is defined by the inability of the adrenal cortex to produce a sufficient amounts of glucocorticoids (GC) and/or mineralocorticoids [1]. Patients with primary adrenal insufficiency (PAI) present with symptoms that result from the lack of both GC and mineralocorticoid secretion [2]; however, central adrenal insufficiency (CAI) is characterized by inappropriate adrenocorticotropin (ACTH) secretion as a result of disease or injury to the hypothalamus or pituitary gland, leading to a failure of adrenal cortisol production [3, 4].

Most signs and symptoms of adrenal insufficiency are nonspecific and present chronically as fatigue, weight loss, postural dizziness and hypotension; however, an acute presentation (adrenal crisis) with severe hypotension, abdominal pain (mimicking and acute abdomen) and hyponatremia is a life-threatening condition $[1,2,5$, 6]. Mineralocorticoid secretion is preserved in patients with CAI; therefore, hyperkalemia and hypotension are typical features in PAI, as well as hyperpigmentation due to enhanced secretion of pro-opiomelanocortin peptides $[1,2]$. Late diagnosis is not uncommon; several authors reported that CAI seems to be a frequently overlooked cause of hospitalization in case of hyponatremia, especially in the elderly $[7,8]$.

Prompt and correct diagnosis is mandatory because adequate hormonal replacement therapy is lifesaving 
$[3,4]$. The measurement of morning serum cortisol is the initial step of diagnosis; however, when cortisol levels are not clearly sufficient or insufficient to respectively exclude or confirm adrenal insufficiency, biochemical testing is recommended. Different basal or stimulated cortisol cutoff levels, mainly developed with different immunoassays, have been proposed in literature; however, in clinical practice, it is mandatory to consider the pretest probability of HPA axis impairment (in terms of the clinical background of the patient) $[3,4,9,10]$.

Patients with adrenal insufficiency require lifelong GC replacement therapy, whose primary aim is to provide an appropriate amount of cortisol at the appropriate time, closely to the circadian cortisol rhythm [3, 11-13]. One of the major drawbacks related to GC substitution therapy is the lack of objective methods or biomarkers able to reveal under- or overreplacement. Therefore, the treatment is guided both by physician's expertise and by subjective health status of the individual $[3,4,13]$.

This review focuses on the diagnosis and management of CAI, considering assay issues, cortisol stimulation and the titration of substitutive treatment.

\section{Is secondary adrenal insufficiency a rare condition? Who should be tested?}

Impaired ACTH secretion could be related to endogenous hypothalamic-pituitary injury or to iatrogenic HPA axis suppression by synthetic GC. In Table 1, we summarize the high-risk population for CAI.

A GC treatment is largely used in general population (up to $2 \%$ ): CAI onset after GC discontinuation is not uncommon and sometimes unrecognized (up to $4 \%$ of patients after nasal GC) [14]. There is no administration form, dosing, treatment duration or underlying disease that could exclude CAI onset, although higher doses and longer use of GC give the highest risk [14, 15]. Considering hospitalized patients with critical illness, transient HPA axis suppression is increasingly observed and reported as relative adrenal insufficiency, a combination of primary and secondary adrenal insufficiency, because both low CRH-ACTH levels and impaired adrenal gland steroidogenesis are observed [16]. Another form of combined primary

Table 1: Etiology and prevalence of acquired CAI.

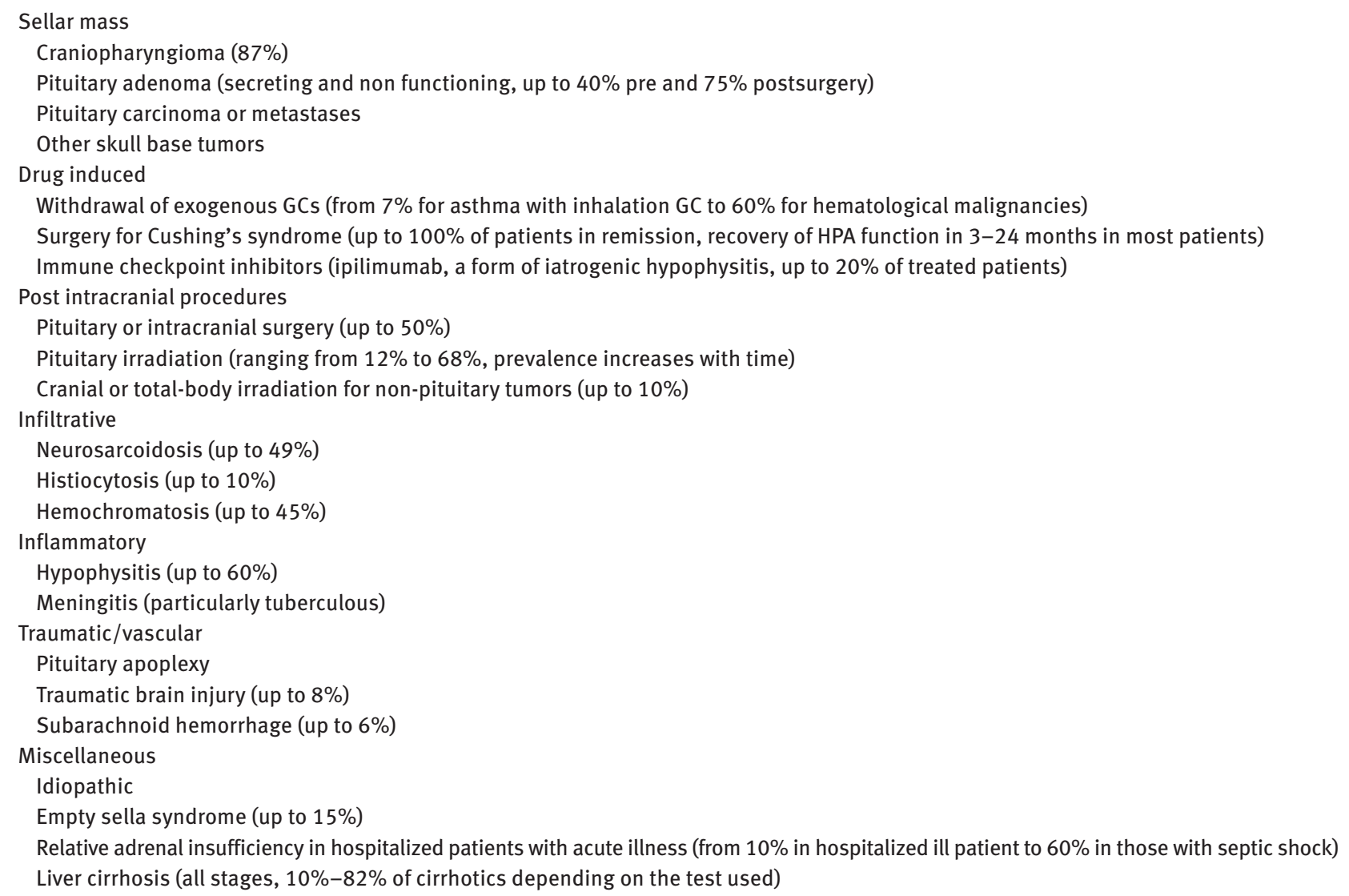


and secondary adrenal insufficiency may occur in liver cirrhosis, where adrenal cortisol secretion is impaired, because of low levels of total cholesterol, and ACTH secretion is reduced, secondary to increased circulating proinflammatory cytokines [17].

Because hypoadrenalism after surgical treatment of endogenous Cushing's syndrome is one of the remission criteria, the development of CAI starts early after the resection of an ACTH- or a cortisol-secreting tumor. Therefore, in this setting, GC substitutive treatment must be started early after surgery and tapered upon physiological recovery of HPA axis [4, 18].

Besides the aforementioned conditions, endogenous CAI is a rare condition, and its prevalence is about 150-280 cases per million inhabitants [4], higher than that reported for PAI (100-140 cases per million) [1]. In patients with pituitary tumors, cranial surgery or irradiation history or brain injury infection, CAI is identified in the formal screening process for hypopituitarism. About one-third of the patients with pituitary failure may present CAI [3, 4, 10, 16, 19-22]. Considering treatment options for pituitary adenoma, medical therapy seems to be protective regarding the integrity of HPA axis, especially in secreting forms [23]. The reported prevalence of CAI after trans-sphenoidal surgery could be up to $50 \%$ in patients with pituitary adenoma [24-28], and 90\% for craniopharyngioma, which usually requires larger or repeated surgical approaches, often combined with radiotherapy [29, 30]. Despite CAI diagnosis, patients need to be reassessed in the follow-up because the HPA axis could recover after surgery in some cases, avoiding unnecessary GC treatment [24]. In 2015, Yedinak et al. [26] reported that the complete recovery rate of HPA axis after surgery in patients with acromegaly was higher than those with non-functioning pituitary adenoma, despite the need for medical therapy, after 7 years of follow-up using $1 \mu \mathrm{g}$ Short Synacthen Test (SST). They discovered 20 new onset of CAI, developed 6-12 weeks after pituitary surgery in a cohort of 100 patients, especially in macroadenomas: $70 \%$ of these new onset CAI resolved after 1 year of observation [26].

CAI is common after pituitary irradiation (ranging from $12 \%$ to $68 \%$ [22, 31, 32]), as well as after cranial radiation for intracerebral or nasopharyngeal tumors and total body irradiation for hematological malignancies. Despite initial cancer, total radiation dose or kind of treatment (being fractionated, proton beam or stereotactic radiotherapy), CAI may take a few years to develop, with incidence of all pituitary hormone deficiencies almost doubling between years 2 and 7 of follow-up [33, 34].

Selected high-risk categories of patients are those after brain injury (traumatic or subarachnoid hemorrhage [13]), infectious meningitis or pituitary abscess [19, 35], and hypophysitis induced by ipilimumab, a monoclonal antibody directed against cytotoxic T-lymphocyte antigen-4 acting as an immune checkpoint inhibitor $[21,36]$.

Reversible, acquired and isolated ACTH deficiency is particularly associated with lymphocytic hypophysitis: the association with pregnancy, the presence of antipituitary antibodies and the radiological features (homogeneous pituitary expansion with stalk thickened) are the clinical hallmarks of hypophysitis [37, 38].

Another critical issue common in hypopituitarism concerns the GH replacement therapy, which could unmask a latent CAI: $\mathrm{GH}$ is able to accelerate the peripheral metabolism of cortisol, revealing an unknown CAI or requiring an increase in current GC dose [39].

\section{What is the rationale for SST?}

The measurement of morning serum cortisol is the initial step of CAI diagnosis: different cutoffs have been proposed; however, it is generally accepted that low morning cortisol levels are indicative of adrenal insufficiency, in both primary and secondary forms. The threshold of morning cortisol level that exclude adrenal insufficiency with a sensitivity of $100 \%$ is uncertain: the choice of a higher cutoff allows to consider also partial HPA axis impairment (common in CAI). The final diagnosis of adrenal insufficiency is highly likely if morning cortisol is $<138 \mathrm{nmol} / \mathrm{L}$ ( $5 \mu \mathrm{g} / \mathrm{dL}$, two samples if clinically feasible) in PAI [1, 2], as well as in CAI [40, 41]. However, to avoid false diagnosis and inappropriate GC treatment, stricter criteria $(<80-100 \mathrm{nmol} / \mathrm{L})$ in one sample are suggested to diagnose CAI $[3,4,10]$.

One of the major drawbacks concerning the diagnosis of adrenal insufficiency (and unfortunately one of the less known) is that the reliability of routine immunoassays is highly variable because an accurate cortisol quantification is compromised by matrix effects, considerable interassay variation and partial antibody specificity, therefore leading to an uncertainty area starting in the range of 100-150 nmol/L [42]. Lack of standardization across different platforms for cortisol measurement is an issue in routine clinical practice because some cutoff values established with immunoassay could not be used with other platforms [43]. Liquid chromatography coupled with tandem mass spectrometry (LC-MS/ MS) offers improved specificity and sensitivity; however, cortisol cutoffs proposed in guidelines did not considered cortisol assays $[1,10,44]$. 
Elevated levels of cortisol-binding globulin in women receiving estrogen treatment may increase total serum cortisol levels; therefore, in some cases, a woman with suspected CAI may present a misleading normal serum cortisol concentration [43]. Contrariwise, morning salivary cortisol level is free: it has been studied in women using oral contraceptive pill or during pregnancy [45], and in suspected adrenal insufficiency with immunometric assay [46] or with LC-MS/MS [47]. However, the diagnostic accuracy of salivary cortisol in suspected adrenal insufficiency is questionable [48], and its routine use is not yet suggested $[1,10]$. High ACTH values and cutaneous hyperpigmentation increase the clinical suspicion of PAI $[1,2]$; nonetheless, the finding of a random low/normal ACTH level may not be helpful in diagnosing CAI $[3,4]$.

When cortisol levels are not clearly sufficient or insufficient to respectively exclude or confirm adrenal insufficiency, biochemical testing with SST is recommended to confirm the diagnosis [10]. Despite the guideline's recommendation, there are a large amount of data showing that almost all patients with an early morning cortisol $>400 \mathrm{nmol} / \mathrm{L}$ pass stimulation tests if modern assays for cortisol are considered, i.e. the recent automated immunoassays Advia Centaur (Siemens), Architect (Abbott) or the Roche Modular System (Roche) [4, 49].

The rationale of SST in CAI is the assumption that the acute responsiveness of the adrenal zona fasciculata is reduced in chronic endogenous corticotropin deficiency; therefore, a rapid ACTH injection fails to stimulate a cortisol response after 30-60 min [40]. However, it is to consider that a patient with partial ACTH deficiency (i.e. with a suboptimal cortisol peak after SST) is likely to have ACTH levels within normal values for most of the day, without functional adrenal atrophy, thus explaining the relative low sensitivity of SST in some cases with partial HPA axis impairment.

Standard (or high, $250 \mu \mathrm{g}$ ) dose SST is recommended in patients with PAI [1]; however, in CAI, both low $(1 \mu \mathrm{g})$ and standard dose SSTs are suggested: a cortisol peak $>500 \mathrm{nmol} / \mathrm{L}$ at 30 or $60 \mathrm{~min}$ is sufficient to exclude CAI [10]. In clinical practice, a significant deviation from this threshold is adopted in $52 \%$ of the $250-\mu$ g SST and $39 \%$ of the 1- $\mu \mathrm{g}$ SST, reflecting the use of locally derived cutoffs, dependent on the assay platform used and the clinical context of the patient $[49,50]$. In this scenario, understanding the pretest probability of ACTH deficiency (the clinical background of the patient: a positive history for pituitary surgery or irradiation, previous or concomitant GC treatment, exposure to cranial or total body irradiation and so on) is essential to properly diagnose CAI because SST had a suboptimal likelihood ratio for a negative test
[9]. To avoid analytical interferences, Endocrine Society's guidelines suggest testing for HPA axis at least 18-24 h after the last hydrocortisone (HC) dose, or after a longer withdrawal for long-acting GC [10].

Because the rationale for SST is the assumption that cortisol response is blunted in chronic ACTH deficiency, it is important to define when we consider the condition that probably will induce the CAI as "chronic". Few papers investigated the optimal time shift to perform SST (suggesting that it can be carried out at least 4 weeks after pituitary surgery $[51,52])$, but the major part of the studies proposed the stimulation test 2-3 months after surgery [53-56]. Therefore, in clinical practice, SST is scheduled 2-3 months after every HPA axis injury. At the best of our knowledge, conclusive data regarding the time of cortisol testing in other different etiologies of CAI (i.e. withdrawal of exogenous GCs, brain injury and so on) are lacking: further studies are needed to establish the optimal time shift to assess HPA axis in these patients.

\section{Standard or low-dose SST: that is the question}

There is an ongoing debate about the optimal dose of corticotropin in SST: it is suggested that $250 \mu \mathrm{g}$ is a supraphysiological stimulus, eliciting very high circulating ACTH levels, therefore excessive to detect mild CAI [56]. In patients with partial endogenous ACTH deficiency, the adrenal responsiveness to high doses of ACTH may be preserved, with a resultant false-negative SST. By contrast, the $1-\mu \mathrm{g}$ dose is known to be the lowest one to induce adrenal response because 0.6 or $0.8 \mu \mathrm{g}$ was not able to increase cortisol levels in healthy controls [57].

Contrasting data about SST diagnostic accuracy are reported: some authors reported a superior role of $1 \mu \mathrm{g}$ $[58,59]$ or $250 \mu \mathrm{g}[52,54,60] \mathrm{SST}$, and others reported that both tests presented similar results $[55,56,61]$.

Kazlauskaite et al. [40] performed a systematic quantitative meta-analysis (600 patients) to compare the performance of the 250- or 1- $\mu \mathrm{g}$ SST in patients with CAI [confirmed with insulin tolerance test (ITT) or metyrapone test], considering only high-risk populations (pituitary or other intracranial tumors, brain surgery or irradiation and hypopituitarism). Half of the patients performed both tests: the 1- $\mu$ g SST had a larger area under the receiver operating characteristic curve than the standard dose, also after adjusting for cortisol assay. Therefore, they concluded that 30-min cortisol values after the 1- $\mu$ g SST presented a better diagnostic performance. Authors also 
suggested a three-step approach for evaluating patients with possible CAI: the first was measuring morning cortisol levels, the second was to perform a $1-\mu \mathrm{g}$ SST if serum cortisol levels were $<138$ or $>365 \mathrm{nmol} / \mathrm{L}$ and the third was to consider ITT or metyrapone test only in indeterminate SST results. This flowchart would be able to diagnose the majority of patients; however, clinical judgment (starting from the clinical background of the patient) would maintain a critical role.

Recently, Ospina et al. [9] included only studies reporting CAI diagnosed with ITT or metyrapone test (1200 adult patients) in a meta-analysis. They concluded that both high and low-dose SSTs had low sensitivity ( $64 \%$ for standard and $83 \%$ for low-dose SST) and high specificity (93\% for $250 \mu \mathrm{g}$ and $86 \%$ for the $1-\mu \mathrm{g} \mathrm{SST}$ ) to diagnose CAI, resulting in a reasonable positive likelihood ratio ( 9 and 6 , respectively) but a suboptimal negative likelihood ratio (0.4 and 0.2, respectively). Therefore, SST is more helpful in ruling in the condition when positive (to confirm CAI in patients with inadequate cortisol response to ACTH), rather than to rule out when negative (to exclude CAI in patients with negative tests, considered as normal cortisol response to ACTH) [9]. Therefore, also the second metaanalysis confirmed that it is mandatory to consider the pretest probability of CAI before prescribing an SST.

To conclude, there is no general consensus regarding which SST is superior because contrasting data are available [52, 54-56, 58-61], the results of the first and second meta-analyses are discordant $[9,40]$ and finally the recent guidelines do not suggest which SST to use (1 or $250 \mu \mathrm{g}$ ) [10]. In our clinical practice, we use the $1-\mu \mathrm{g}$ SST (to reduce false-negative results) combined with the clinical history of the patient (to rule out CAI in case of suboptimal cortisol response).

\section{How should SST be prepared and performed?}

During the 250- $\mu$ g SST, cortisol levels are obtained at baseline (in the morning between 8:00 and 9:00 a.m.) and after ACTH injection (most commonly at 30 or $60 \mathrm{~min}$ ). Some authors found that $30 \mathrm{~min}$ is the maximum response for the low dose, and then cortisol levels started to decrease, whereas using the high-dose SST, there is still a little cortisol increase from 30 to $60 \mathrm{~min}$, not only in healthy controls but also in patients with known impaired HPA axis [55].

The concentration of $250 \mu \mathrm{g}$ is a ready-to-use formulation (Synacthen ${ }^{\circledR}$ or Cortrosyn $^{\circledR}$ ); otherwise, $1 \mu \mathrm{g} / \mathrm{mL}$ is obtained by diluting a vial of ACTH (available in $250 \mu \mathrm{g} / \mathrm{mL}$ ) in $249 \mathrm{~mL}$ of sterile saline physiological solution $\mathrm{NaCl}$ $0.9 \%$ and then aspirating $1 \mathrm{~mL}$ of solution [23]. Another preparation is to extract $0.4 \mathrm{~mL}$ from a $1-\mathrm{mL}$ vial of 250 $\mu \mathrm{g}$ and add it to a $100-\mathrm{mL}$ physiological solution, resulting in an ACTH concentration of $100 \mu \mathrm{g} / 100 \mathrm{~mL}$, and then $1 \mathrm{~mL}$ of this solution could be injected [56]. Some authors suggest to add all the $250-\mu \mathrm{g}$ ampule to $49 \mathrm{~mL}$ of $0.9 \%$ saline, then adding $0.2 \mathrm{~mL}$ of these latter solution $(5 \mu \mathrm{g} /$ $\mathrm{mL}$ ) to $0.8 \mathrm{~mL}$ of $0.9 \%$ saline (obtaining $1 \mu \mathrm{g} / \mathrm{mL}$ ) [62]. To conclude, up to 10 dilution methods for the $1-\mu \mathrm{g}$ SST have been reported, resulting in dose variation (up to $0.8 \mu \mathrm{g}$ ) and so in false results, with potentially important clinical sequelae [50].

Another interesting, and crucial if unknown, issue of SST is the loss of ACTH through tubing. In 2010, Wade et al. [63] measured the ACTH concentrations in both diluted and administered solutions, reporting that about $25 \mathrm{~cm}$ of tubing was able to reduce the amount of injected ACTH of $22-59 \%$.

To conclude, loss of ACTH during dilution (with different protocol adopted in different centers) or administration might sharply reduce the cortisol response when $1 \mu \mathrm{g}$ of ACHT is used. In this scenario, a $1 \mu \mathrm{g}$ vial is needed from the factory, and direct venous injection is suggested to reduce, at least in part, some bias connected to corticotropin test.

\section{How to manage indeterminate/ unreliable SST?}

Because CAI is a life-threatening condition, both falsenegative and false-positive SST results are detrimental for the patients. Other tests have been used, or are currently used, as ITT, metyrapone test or glucagon test (summarized in Table 2). Although the CRH test has a theoretical role to distinguish hypothalamic from pituitary disease, it is no longer recommended $[3,10]$.

ITT is considered the gold standard to diagnose CAI because the response of the HPA axis to hypoglycemia $(<2.2 \mathrm{mmol} / \mathrm{L})$ constitutes an evidence of sufficient physiological stress to provoke ACTH release, not only in case of surgical stress $[3,4,10]$. ITT could be used also to assess the integrity of somatotroph function; however, other tests are suggested to diagnose GH deficiency [64, 65]. As SST, it is unnecessary to perform an ITT in subjects with low morning cortisol levels. Insulin and glucagon tests could be performed in acute setting, early after suspected HPA axis injury, when the knowledge of the necessity for GC replacement therapy is paramount. Despite the 


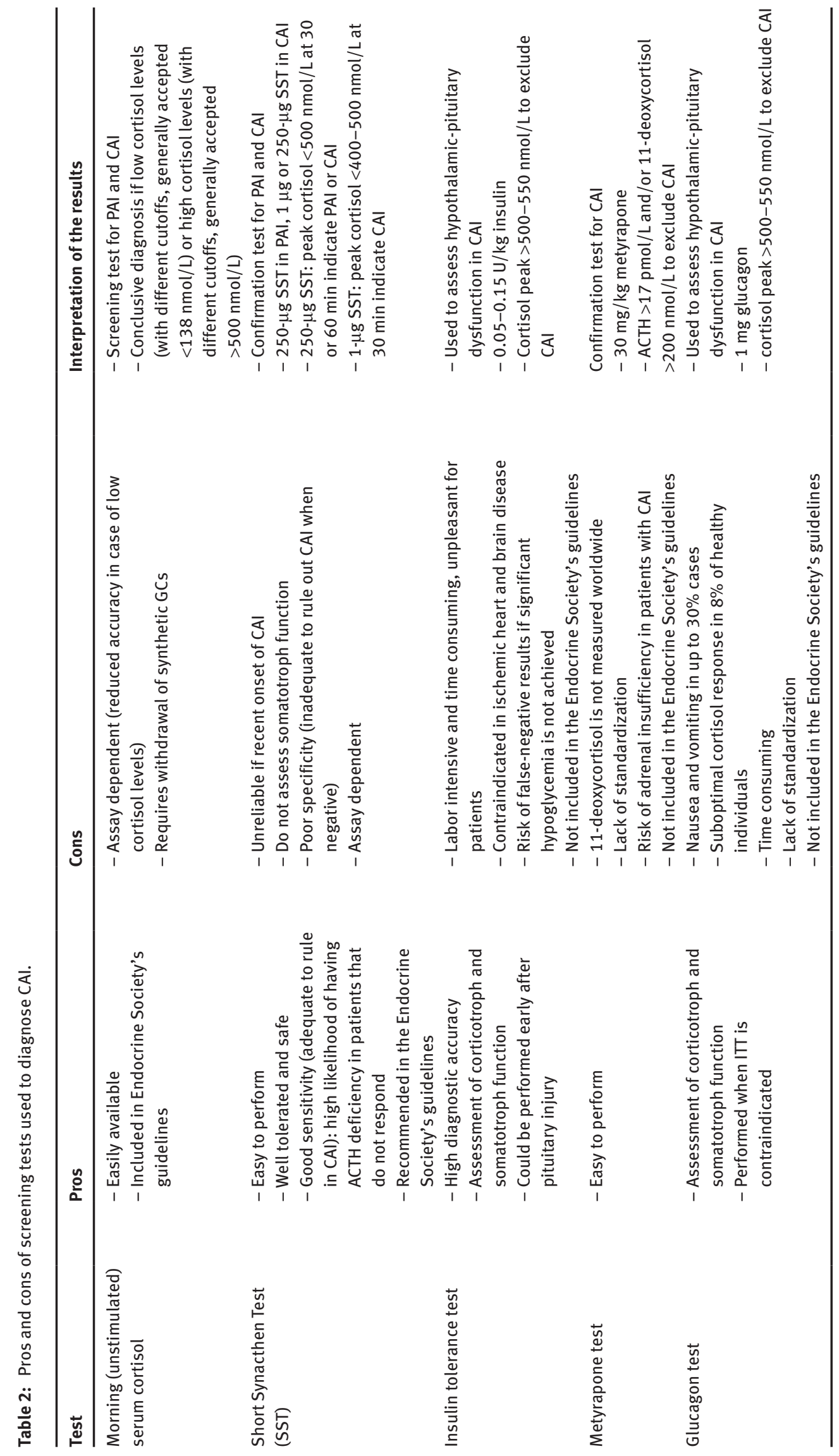


risks correlated to hypoglycemia, the main limitations of the ITT are that it requires the supervision of physicians or nurses and it is contraindicated in the elderly or in those individuals with seizures or cardiocerebrovascular disease.

Overnight metyrapone test is considered convenient and sensitive, compared with the ITT; the diagnostic accuracy of this test is related to an increase in 11-deoxycortisol levels $>200-260 \mathrm{nmol} / \mathrm{L}$ [55, 62]. Metyrapone is administered orally $30 \mathrm{mg} / \mathrm{kg}$ before sleeping, and blood is sampled the following morning for 11-deoxycortisol and ACTH. When directly compared with SST, some authors reported that metyrapone test presented an increased [62] or similar [55] sensitivity to diagnose CAI. Nevertheless, metyrapone is not available worldwide (i.e. in the US), and metyrapone test is not mentioned in the Endocrine Society's guidelines for hypopituitarism [10]. Further studies are needed to assess its role in the diagnostic flowchart of CAI.

\section{GC replacement therapy in CAI}

A careful cost-benefit analysis is suggested in the era of personalized medicine because a combination of various treatment (especially surgery and radiotherapy) could increase the risk of hypopituitarism and CAI-related mortality [22, 23, 66-69].

Patients with CAI require lifelong GC replacement therapy, whose primary aim is to replicate as much as possible the circadian cortisol rhythm [3, 11-13]. Substitutive therapy in adrenal insufficiency should be able to provide an appropriate amount of cortisol at the appropriate time: one of the major drawbacks related to currently available oral GC formulations is their lack of ability to properly replicate the physiologic cortisol circadian rhythm. Therefore, well-being is often not fully restored in all patients, and life expectancy may even be reduced $[12,70]$.

Recently, it has been established that the daily cortisol production rate ranges between 5 and $10 \mathrm{mg} / \mathrm{m}^{2}$ of body surface area [71], which is lower than that previously considered. Traditionally, the daily HC dose was $30 \mathrm{mg} /$ day, split into two or three doses (with the highest in the morning); given the recent discovery of lower levels of cortisol production rates, the "traditional $30 \mathrm{mg}$ of HC" was supraphysiological [70]. Moreover, higher doses of HC replacement therapy ( $>25 \mathrm{mg} /$ day) are related to increased mortality in patients with acromegaly, especially for cardiovascular disease (up to $44 \%$ mortality if $\mathrm{HC}$ therapy was $>30 \mathrm{mg} /$ day) [69]. Also, patients with non-functioning pituitary adenoma that developed CAI presented increased mortality if receiving $>20 \mathrm{mg} /$ day of HC [28]. All synthetic compounds could be used to treat adrenal insufficiency, but in clinical practice, short halflife GCs [HC and cortisone acetate (CA)] are preferred than those with longer half-life (as prednisolone, usually given as a single morning dose of 3-5 mg [72], or dexamethasone $0.375-0.5 \mathrm{mg}$, preferred in adults with congenital adrenal hyperplasia [73]).

Filipsson et al. [74] have described, in a large series of more than 1500 patients with ACTH deficiency, an adverse metabolic profile in patients taking higher doses of GCs, with increased total cholesterol, triglycerides, waist circumference and glycosylated hemoglobin compared with the ACTH-sufficient patients. Intriguingly, those subjects who had HC-equivalent doses $<20 \mathrm{mg} /$ day did not differ in metabolic end points compared with the ACTH-sufficient patients. Moreover, they observed that patients receiving $\mathrm{HC}$ were at high risk to develop an adverse metabolic profile (especially regarding glucose metabolism) than those using CA.

After the synthesis of cortisone in 1950 [70], the treatment regimens remained almost unchanged: the short elimination half-life of HC (approximately $1.5 \mathrm{~h}$ ) when given in traditional immediate-release preparations twice or thrice daily leads, however, to high peaks with low trough values in between. More than 1200 patients with adrenal insufficiency (11\% with CAI) reported in a webbased survey that there is the need for improvement in the daily management of adrenal insufficiency because the negative impact of their treatment on subjective health was consistent [75].

Recently, novel HC preparations (dual-release HC) have been developed, allowing a cortisol serum profile closer to circadian secretion, improving the treatment of patients with CAI [76-79]. In PAI, dual-release HC is able to ameliorate glucose metabolism, to improve cardiovascular risk factors (especially weight, waist circumference, blood pressure and cholesterol levels) $[76,78]$ and to reduce recurrent infections [80]. On the contrary, there really are too few data in CAI to recommend the use of dual-release $\mathrm{HC}$ to improve metabolic parameters.

\section{Management of therapy adequacy}

In clinical practice, achieving the correct replacement dose is a challenge, especially to identify the lowest GC dose that relieves symptoms of insufficiency, while avoiding cortisol excess. 
Several authors proposed serum, salivary or urinary biomarkers, but none has been extensively studied. Mah et al. [81] suggested a normative graph to evaluate the replacement therapy. Considering the nomogram, one sample of serum cortisol 2.5-5 h after the first administration of GC therapy compared with reference percentiles should be used for individual adjustment. Nevertheless, this protocol requires blood sample collection and could be inconvenient to manage for both outpatients and physicians; moreover, it has been used only in the original 20 patients of the cohort and not replicated by other groups.

In 2012, we described that multiple saliva collections could be used to measure salivary cortisol and to compute area under the curve (to assess daily GC exposure), in a small group of patients with CAI treated with CA. Multiple saliva sampling, a convenient easy-to-manage and stressfree tool for outpatients, could pave the way to a future application of salivary cortisol assays for assessing the adequacy of replacement therapy because samples could be performed before and after GC dose [47, 82]. Recently, we reported, in a proof-of-concept prospective study, that the reduction of GC treatment (assessed with daily salivary cortisol) resulted in a better replication of circadian cortisol rhythm and in an improvement of diastolic blood pressure [83].

Urinary free cortisol excretion fails to detect daily fluctuations of cortisol (secondary to treatment) and suffers of a marked day-to-day variability depending on renal function [11, 84]. A clinical score was proposed by Arlt et al. [85], but subsequent studies did not support the superiority of this qualitative system over quantitative methods.

\section{Controversies and areas of uncertainty}

The long-term natural history of patients with pituitary disease and the risk to develop CAI during the followup are still unknown, as well as reliable biomarkers to assess the adequacy of substitutive GC therapy. Therefore, efforts should be considered to answer the following questions:

- The choice between standard $(250 \mu \mathrm{g})$ or low $(1 \mu \mathrm{g})$ SST in CAI is still uncertain, despite several case-control studies and two meta-analyses.

- How to manage patients with low/normal cortisol levels and inadequate response to SST. Obviously, the proposed thresholds are based on the meta-analyses of well-designed studies and considering ITT as gold standard for AI diagnosis; nevertheless, for those patients with an intermediate morning serum cortisol measurement (200 nmol/L) and suboptimal peak after SST (i.e. $350 \mathrm{nmol} / \mathrm{L}$ ) or for whom observation is not appropriate, other diagnostic tools should be performed.

- The impact in mimicking the physiological circadian cortisol profile by dual-release $\mathrm{HC}$ formulations has to be further investigated in patients with CAI, as well as the close relationship among cortisol substitutive therapy and other treatments (in order of replacement levothyroxine, estrogens and growth hormone).

- How to assess the adequacy of cortisol treatment is a critical issue because several clinical or biochemical markers have been proposed and none has been shown to be superior in routine clinical practice.

\section{Conclusions}

A functional HPA axis is essential for normal health and life expectancy. Therefore, CAI is a life-threatening disorder associated with increased morbidity and mortality: correct diagnosis and treatment are crucial for well-being and lifesaving.

The milestones of CAI are not only the measurements of basal serum cortisol and dynamic tests: the medical history is crucial because the diagnostic accuracy biochemical of tests is not definitely reliable in all patients. Nevertheless, SST is one of the most used, at least $6-8$ weeks after surgery, because cortisol response is blunted in chronic ACTH deficiency.

The management of therapy adequacy needs a careful evaluation because both excessive and insufficient treatments are correlated to increased morbidity and mortality.

Acknowledgments: The authors are grateful to Prof. Franco Mantero for the critical review of the manuscript.

Author contributions: All the authors have accepted responsibility for the entire content of this submitted manuscript and approved submission.

Research funding: None declared.

Employment or leadership: None declared.

Honorarium: None declared.

Competing interests: The funding organization(s) played no role in the study design; in the collection, analysis and interpretation of data; in the writing of the report; or in the decision to submit the report for publication. 


\section{References}

1. Bornstein SR, Allolio B, Arlt W, Barthel A, Don-Wauchope A, Hammer GD, et al. Diagnosis and treatment of primary adrenal insufficiency: an Endocrine Society clinical practice guideline. J Clin Endocrinol Metab 2016;101:364-89.

2. Husebye ES, Allolio B, Arlt W. Consensus statement on the diagnosis, treatment and follow-up of patients with primary adrenal insufficiency. J Intern Med 2014;275:104-15.

3. Grossman AB. The diagnosis and management of central hypoadrenalism. J Clin Endocrinol Metab 2010;95:4855-63.

4. Crowley RK, Argese N, Tomlinson JW, Stewart PM. Central hypoadrenalism. J Clin Endocrinol Metab 2014;99:4027-36.

5. Hahner S, Loeffler M, Bleicken B, Drechsler C, Milovanovic D, Fassnacht $M$, et al. Epidemiology of adrenal crisis in chronic adrenal insufficiency: the need for new prevention strategies. Eur J Endocrinol 2010;162:597-602.

6. Hahner S, Spinnler C, Fassnacht M, Burger-Stritt S, Lang K, Milovanovic D, et al. High incidence of adrenal crisis in educated patients with chronic adrenal insufficiency: a prospective study. J Clin Endocrinol Metab 2015;100:407-16.

7. Chanson P. Severe hyponatremia as a frequent revealing sign of hypopituitarism after 60 years of age. Eur J Endocrinol 2003;149:177-8.

8. Diederich S, Franzen NF, Bahr V, Oelkers W. Severe hyponatremia due to hypopituitarism with adrenal insufficiency: report on 28 cases. Eur J Endocrinol 2003;148:609-17.

9. Ospina NS, Al Nofal A, Bancos I, Javed A, Benkhadra K, Kapoor E, et al. ACTH stimulation tests for the diagnosis of adrenal insufficiency: systematic review and meta-analysis. J Clin Endocrinol Metab 2016;101:427-34.

10. Fleseriu M, Hashim IA, Karavitaki N, Melmed S, Murad MH, Salvatori $\mathrm{R}$, et al. Hormonal replacement in hypopituitarism in adults: an Endocrine Society clinical practice guideline. J Clin Endocrinol Metab 2016;101:3888-921.

11. Debono M, Price JN, Ross RJ. Novel strategies for hydrocortisone replacement. Best Pr Res Clin Endocrinol Metab 2009;23:221-32.

12. Debono M, Ross RJ, Newell-Price J. Inadequacies of glucocorticoid replacement and improvements by physiological circadian therapy. Eur J Endocrinol 2009;160:719-29.

13. Grossman A, Johannsson G, Quinkler M, Zelissen P. Therapy of endocrine disease: perspectives on the management of adrenal insufficiency: clinical insights from across Europe. Eur J Endocrinol 2013;169:R165.

14. Broersen LH, Pereira AM, Jørgensen JO, Dekkers OM. Adrenal insufficiency in corticosteroids use: systematic review and metaanalysis. J Clin Endocrinol Metab 2015;100:2171-80.

15. Dinsen S, Baslund B, Klose M, Rasmussen AK, Friis-Hansen L, Hilsted L, et al. Why glucocorticoid withdrawal may sometimes be as dangerous as the treatment itself. Eur J Intern Med 2013;24:714-20.

16. Reddy P. Clinical approach to adrenal insufficiency in hospitalised patients. Int J Clin Pract 2011;65:1059-66.

17. Karagiannis AK, Nakouti T, Pipili C, Cholongitas E. Adrenal insufficiency in patients with decompensated cirrhosis. World J Hepatol 2015;7:1112.

18. Nieman LK, Biller BM, Findling JW, Murad MH, Newell-Price J, Savage MO, et al. Treatment of Cushing's syndrome: an Endocrine Society clinical practice guideline. J Clin Endocrinol Metab 2015;100:2807-31.
19. Tsiakalos A, Xynos ID, Sipsas NV, Kaltsas G. Pituitary insufficiency after infectious meningitis: a prospective study. J Clin Endocrinol Metab 2010;95:3277-81.

20. Aimaretti G, Ambrosio MR, Di Somma C, Gasperi M, Cannavò S, Scaroni $C$, et al. Residual pituitary function after brain injuryinduced hypopituitarism: a prospective 12-month study. J Clin Endocrinol Metab 2005;90:6085-92.

21. Brilli L, Danielli R, Ciuoli C. Prevalence of hypophysitis in a cohort of patients with metastatic melanoma and prostate cancer treated with ipilimumab. Endocrine 2017;58:535-41.

22. Darzy KH. Radiation-induced hypopituitarism. Curr Opin Endocrinol Diabetes Obes 2013;20:342-53.

23. Ceccato F, Lizzul L, Zilio M, Barbot M, Denaro L, Emanuelli E, et al. Medical treatment for acromegaly does not increase the risk of central adrenal insufficiency: a long-term follow-up study. Horm Metab Res 2016;48:514-9.

24. Webb SM, Rigla M, Wägner A, Oliver B, Bartumeus F. Recovery of hypopituitarism after neurosurgical treatment of pituitary adenomas. J Clin Endocrinol Metab 1999;84:3696-700.

25. Jahangiri A, Wagner J, Han SW, Tran MT, Miller LM, Tom MW, et al. Rate and time course of improvement in endocrine function after more than 1000 pituitary operations. Neurosurgery 2014;61(Suppl 1):163-6.

26. Yedinak C, Hameed N, Gassner M, Brzana J, McCartney S, Fleseriu $M$. Recovery rate of adrenal function after surgery in patients with acromegaly is higher than in those with non-functioning pituitary tumors: a large single center study. Pituitary 2015;18:701-9.

27. Berker M, Hazer DB, Yücel T, Gürlek A, Cila A, Aldur M, et al. Complications of endoscopic surgery of the pituitary adenomas: analysis of 570 patients and review of the literature. Pituitary 2012;15:288-300.

28. Hammarstrand C, Ragnarsson O, Hallén T, Andersson E, Skoglund T, Nilsson AG, et al. Higher glucocorticoid replacement doses are associated with increased mortality in patients with pituitary adenoma. Eur J Endocrinol 2017;177:251-6.

29. Crowley RK, Hamnvik OP, O’Sullivan EP, Behan LA, Smith D, Agha $A$, et al. Morbidity and mortality in patients with craniopharyngioma after surgery. Clin Endocrinol (Oxf) 2010;73:516.

30. Wijnen $M$, van den Heuvel-Eibrink $M$, Janssen J. Very long-term sequelae of craniopharyngioma. Eur J Endocrinol 2017;176:755-67.

31. Minniti G, Traish D, Ashley S, Gonsalves A, Brada M. Fractionated stereotactic conformal radiotherapy for secreting and nonsecreting pituitary adenomas. Clin Endocrinol (Oxf) 2006;64:542-8.

32. Li X, Li Y, Cao Y, Li P, Liang B, Sun J, et al. Safety and efficacy of fractionated stereotactic radiotherapy and stereotactic radiosurgery for treatment of pituitary adenomas: a systematic review and meta-analysis. J Neurol Sci 2017;372:110-16.

33. Appelman-Dijkstra NM, Kokshoorn NE, Dekkers OM, Neelis KJ, Biermasz NR, Romijn JA, et al. Pituitary dysfunction in adult patients after cranial radiotherapy: systematic review and metaanalysis. J Clin Endocrinol Metab 2011;96:2330-40.

34. Kyriakakis N, Lynch J, Orme SM, Gerrard G, Hatfield P, Loughrey $C$, et al. Pituitary dysfunction following cranial radiotherapy for adult-onset nonpituitary brain tumours. Clin Endocrinol (Oxf) 2016;84:372-9.

35. Gao L, Guo X, Tian R, Wang Q, Feng M, Bao X, et al. Pituitary abscess: clinical manifestations, diagnosis and treatment of 66 cases from a large pituitary center over 23 years. Pituitary 2017;20:189-94. 
36. Torino F, Corsello SM, Salvatori R. Endocrinological side-effects of immune checkpoint inhibitors. Curr Opin Oncol 2016;28: 278-87.

37. Lupi I, Manetti L, Raffaelli V, Lombardi M, Cosottini M, Iannelli A, et al. Diagnosis and treatment of autoimmune hypophysitis: a short review. J Endocrinol Invest 2011;34:e245.

38. Glezer A, Bronstein M. Pituitary autoimmune disease: nuances in clinical presentation. Endocrine 2012;42:74-9.

39. Scaroni C, Ceccato F, Rizzati S, Mantero F. Concomitant therapies (glucocorticoids and sex hormones) in adult patients with growth hormone deficiency. J Endocrinol Invest 2008;31(Suppl):61-5.

40. Kazlauskaite R, Evans AT, Villabona CV, Abdu TA, Ambrosi B, Atkinson $A B$, et al. Corticotropin tests for hypothalamic-pituitary-adrenal insufficiency: a metaanalysis. J Clin Endocrinol Metab 2008;93:4245-53.

41. Chanson P, Guignat L, Goichot B, Chabre O, Boustani DS, Reynaud $R$, et al. Adrenal insufficiency: screening methods and confirmation of diagnosis. Ann Endocrinol (Paris) 2017;78:495-511.

42. Hawley JM, Owen LJ, Lockhart SJ, Monaghan PJ, Armston A, Chadwick CA, et al. Serum cortisol: an up-to-date assessment of routine assay performance. Clin Chem 2016;62:1220-9.

43. Gounden V, Rampursat YD, Jialal I. Secretory tumors of the pituitary gland: a clinical biochemistry perspective. Clin Chem Lab Med 2018;57:150-64.

44. El-Farhan N, Rees DA, Evans C. Measuring cortisol in serum, urine and saliva-are our assays good enough? Ann Clin Biochem 2017;54:308-22.

45. Manetti L, Rossi G, Grasso L, Raffaelli V, Scattina I, Del Sarto S, et al. Usefulness of salivary cortisol in the diagnosis of hypercortisolism: comparison with serum and urinary cortisol. Eur J Endocrinol 2013;168:315-21.

46. Ceccato F, Barbot M, Zilio M, Ferasin S, Occhi G, Daniele A, et al. Performance of salivary cortisol in the diagnosis of Cushing's syndrome, adrenal incidentaloma, and adrenal insufficiency. Eur J Endocrinol 2013;169:31-6.

47. Ceccato F, Selmin E, Sabbadin C, Dalla Costa M, Antonelli G, Plebani M, et al. Improved salivary cortisol rhythm with dualrelease hydrocortisone. Endocr Connect 2018;7:965-97.

48. Raff H. Utility of salivary cortisol measurements in Cushing's syndrome and adrenal insufficiency. J Clin Endocrinol Metab 2009;94:3647-55.

49. Sbardella E, Isidori AM, Woods CP, Argese N, Tomlinson JW, Shine B, et al. Baseline morning cortisol level as a predictor of pituitary-adrenal reserve: a comparison across three assays. Clin Endocrinol (Oxf) 2017;86:177-84.

50. Cross AS, Helen Kemp E, White A, Walker L, Meredith S, Sachdev $P$, et al. International survey on high- and low-dose synacthen test and assessment of accuracy in preparing low-dose synacthen. Clin Endocrinol (Oxf) 2018;88:744-51.

51. Dökmetaş HS, Colak R, Keleştimur F, Selçuklu A, Unlühizarci $\mathrm{K}$, Bayram F. A comparison between the 1-microg adrenocorticotropin (ACTH) test, the short ACTH (250 microg) test, and the insulin tolerance test in the assessment of hypothalamopituitary-adrenal axis immediately after pituitary surgery. J Clin Endocrinol Metab 2000;85:3713-9.

52. Courtney CH, McAllister AS, Bell PM, McCance DR, Leslie H, Sheridan B, et al. Low- and standard-dose corticotropin and insulin hypoglycemia testing in the assessment of hypothalamic-pituitary-adrenal function after pituitary surgery. J Clin Endocrinol Metab 2004;89:1712-7.
53. Ambrosi B, Barbetta L, Re T, Passini E, Faglia G. The one microgram adrenocorticotropin test in the assessment of hypothalamic-pituitary-adrenal function. Eur J Endocrinol 1998;139:575-9.

54. Tordjman K, Jaffe A, Trostanetsky Y, Greenman Y, Limor R, Stern N. Low-dose $(1 \mu \mathrm{g})$ adrenocorticotrophin (ACTH) stimulation as a screening test for impaired hypothalamo-pituitaryadrenal axis function: sensitivity, specificity and accuracy in comparison with the high-dose $(250 \mu \mathrm{g})$ test. Clin Endocrinol (Oxf) 2000;52:633-40.

55. Giordano R, Picu A, Bonelli L, Balbo M, Berardelli R, Marinazzo $E$, et al. Hypothalamus-pituitary-adrenal axis evaluation in patients with hypothalamo-pituitary disorders: comparison of different provocative tests. Clin Endocrinol (Oxf) 2008;68:935-941.

56. Dekkers OM, Smit JW, Romijn JA, Pereira AM. Comparison of the cortisol responses to testing with two doses of ACTH in patients with suspected adrenal insufficiency. Eur J Endocrinol 2011;164:83-7.

57. Dickstein G, Spigel D, Arad E, Shechner C. One microgram is the lowest ACTH dose to cause a maximal cortisol response. There is no diurnal variation of cortisol response to submaximal ACTH stimulation. Eur J Endocrinol 1997;137:172-5.

58. Abdu TA, Elhadd TA, Neary R, Clayton RN. Comparison of the low dose short synacthen test $(1 \mu \mathrm{g})$, the conventional dose short synacthen test $(250 \mu \mathrm{g})$, and the insulin tolerance test for assessment of the hypothalamo-pituitary-adrenal axis in patients with pituitary disease. J Clin Endocrinol Metab 1999;84:838-43.

59. Maghnie M, Uga E, Temporini F, Di lorgi N, Secco A, Tinelli C, et al. Evaluation of adrenal function in patients with growth hormone deficiency and hypothalamic-pituitary disorders: comparison between insulin-induced hypoglycemia, low-dose ACTH, standard ACTH and CRH stimulation tests. Eur J Endocrinol 2005;152:735-41.

60. Cho HY, Kim JH, Kim SW, Shin CS, Park KS, Kim SW, et al. Different cut-off values of the insulin tolerance test, the high-dose short Synacthen test $(250 \mu \mathrm{g})$ and the low-dose short Synacthen test $(1 \mu \mathrm{g})$ in assessing central adrenal insufficiency. Clin Endocrinol 2014;81:77-84.

61. Mayenknecht J, Diederich S, Bähr V, Plöckinger U, Oelkers W. Comparison of low and high dose corticotropin stimulation tests in patients with pituitary disease. J Clin Endocrinol Metab 1998;83:1558-62.

62. Soule S, Van Zyl Smit C, Parolis G, Attenborough S, Peter D, Kinvig S, et al. The low dose ACTH stimulation test is less sensitive than the overnight metyrapone test for the diagnosis of secondary hypoadrenalism. Clin Endocrinol (Oxf) 2000;53:221-7.

63. Wade M, Baid S, Calis K, Raff H, Sinaii N, Nieman L. Technical details influence the diagnostic accuracy of the 1 microg ACTH stimulation test. Eur J Endocrinol 2010;162:109-13.

64. Corneli G, Di Somma C, Baldelli R, Rovere S, Gasco V, Croce $\mathrm{CG}$, et al. The cut-off limits of the $\mathrm{GH}$ response to $\mathrm{GH}$-releasing hormone-arginine test related to body mass index. Eur J Endocrinol 2005;153:257-64.

65. Molitch ME, Clemmons DR, Malozowski S, Merriam GR, Vance ML. Evaluation and treatment of adult growth hormone deficiency: an Endocrine Society clinical practice guideline. J Clin Endocrinol Metab 2011;96:1587-609.

66. Schöfl C, Grussendorf M, Honegger J, Tönjes A, ThyrokeGronostay D, Mayr B, et al. Failure to achieve disease control 
in acromegaly: cause analysis by a registry-based survey. Eur J Endocrinol 2015;172:351-6.

67. Puig Domingo M. Treatment of acromegaly in the era of personalized and predictive medicine. Clin Endocrinol (Oxf) 2015;83: 3-14.

68. Newell-Price J, Trainer P, Besser M, Grossman A. The diagnosis and differential diagnosis of Cushing's syndrome and pseudoCushing's states. Endocr Rev 1998;19:647-72.

69. Sherlock M, Reulen RC, Alonso AA, Ayuk J, Clayton RN, Sheppard MC, et al. ACTH deficiency, higher doses of hydrocortisone replacement, and radiotherapy are independent predictors of mortality in patients with acromegaly. J Clin Endocrinol Metab 2009;94:4216-23.

70. Hahner S, Allolio B. Therapeutic management of adrenal insufficiency. Best Pract Res Clin Endocrinol Metab 2009;23:167-79.

71. Kraan GP. The daily cortisol production reinvestigated in healthy men. The serum and urinary cortisol production rates are not significantly different. J Clin Endocrinol Metab 1998;83:1247-52.

72. Smith DJ, Prabhudev H, Choudhury S, Meeran K. Prednisolone has the same cardiovascular risk profile as hydrocortisone in glucocorticoid replacement. Endocr Connect 2017;6:766-72.

73. Merke DP. Approach to the adult with congenital adrenal hyperplasia due to 21-hydroxylase deficiency. J Clin Endocrinol Metab 2008;93:653-60.

74. Filipsson H, Monson JP, Koltowska-Häggström M, Mattsson A, Johannsson $\mathrm{G}$. The impact of glucocorticoid replacement regimens on metabolic outcome and comorbidity in hypopituitary patients. J Clin Endocrinol Metab 2006;91:3954-61.

75. Forss M, Batcheller G, Skrtic S, Johannsson G. Current practice of glucocorticoid replacement therapy and patient-perceived health outcomes in adrenal insufficiency-a worldwide patient survey. BMC Endocr Disord 2012;12:8.

76. Johannsson G, Nilsson AG, Bergthorsdottir R, Burman P, Dahlqvist $P$, Ekman B, et al. Improved cortisol exposure-time profile and outcome in patients with adrenal insufficiency: a prospective randomized trial of a novel hydrocortisone dual-release formulation. J Clin Endocrinol Metab 2012;97:473-81.
77. Quinkler M, Miodini Nilsen R, Zopf K, Ventz M, Øksnes M. Modified-release hydrocortisone decreases $\mathrm{BMI}$ and $\mathrm{HbA}_{1 \mathrm{c}}$ in patients with primary and secondary adrenal insufficiency. Eur J Endocrinol 2015;172:619.

78. Giordano R, Guaraldi F, Marinazzo E, Fumarola F, Rampino A, Berardelli $R$, et al. Improvement of anthropometric and metabolic parameters, and quality of life following treatment with dual-release hydrocortisone in patients with Addison's disease. Endocrine 2016;51:360-8.

79. Nilsson AG, Bergthorsdottir R, Burman P. Long-term safety of once-daily, dual-release hydrocortisone in patients with adrenal insufficiency: a phase 3b, open-label, extension study. Eur J Endocrinol 2017:360-8.

80. Isidori AM, Venneri MA, Graziadio C, Simeoli C, Fiore D, Hasenmajer V, et al. Effect of once-daily, modified-release hydrocortisone versus standard glucocorticoid therapy on metabolism and innate immunity in patients with adrenal insufficiency (DREAM): a single-blind, randomised controlled trial. Lancet Diabetes Endocrinol 2018;6:173-85.

81. Mah PM, Jenkins RC, Rostami-Hodjegan A, Newell-Price J, Doane A, Ibbotson V, et al. Weight-related dosing, timing and monitoring hydrocortisone replacement therapy in patients with adrenal insufficiency. Clin Endocrinol (Oxf) 2004;61:367-75.

82. Ceccato F, Albiger N, Reimondo G, Frigo AC, Ferasin S, Occhi G, et al. Assessment of glucocorticoid therapy with salivary cortisol in secondary adrenal insufficiency. Eur J Endocrinol 2012; 167:769-76.

83. Ceccato F, Barbot M, Lizzul L, Selmin E, Saller A, Albiger N, et al. Decrease in salivary cortisol levels after glucocorticoid dose reduction in patients with adrenal insufficiency: a prospective proof-of-concept study. Clin Endocrinol (Oxf) 2018;88: 201-8.

84. Monson JP. The assessment of glucocorticoid replacement therapy. Clin Endocrinol (Oxf) 1997;46:269-70.

85. Arlt W, Rosenthal C, Hahner S, Allolio B. Quality of glucocorticoid replacement in adrenal insufficiency: clinical assessment vs. timed serum cortisol measurements. Clin Endocrinol (Oxf) 2006;64:384-9. 